\title{
POSTER, POSTER ON THE WALL, DO YOU REALLY MEAN IT ALL?
}

\section{DECODING VISUAL METAPHOR ‘GLOBAL WARMING’ IN PUBLIC AWARENESS CAMPAIGNS}

\author{
MARINA PLATONOVA \\ Riga Technical University, Latvia \\ marina.platonova@rtu.lv
}

\begin{abstract}
The tendency to create messages using the elements belonging to different semiotic systems shifts our perception of a communicative act, contributing to the establishment of multimodal and intersemiotic communication practice.

A visual metaphor is seen as one of the instances of a multimodal and intersemiotic message, which generates a text that is revealed gradually, uncovering numerous layers of meaning encoded within a metaphor and within visual, linguistic, and spatial settings it is placed in. The paper sets out to explore the notion of a visual metaphor and focuses on the application of the visual metaphor ' $g$ lobal warming' on posters created for the needs of public awareness campaigns, investigating simultaneous manifestation of iconic and metaphorical mappings in the given visual metaphor.
\end{abstract}

Keywords: environmental communication, iconicity, intersemiotic communication, intermediality, poster analysis, public awareness campaign, semiotic systems, visual metaphor

\section{Introduction}

In the contemporary knowledge society that "promotes multiple forms of semiotic systems" (Iyer and Luke 2010: 21), the process of information transfer calls for extensive multiliteracy on the part of the message recipients especially in the dynamically developing research fields.

The emerging interdisciplinary field of environmental communication represents the combination of special codes typical of not only distinct scientific domains, but even of different symbolic systems, as it communicates meaning "through the system of common symbols, signs and behavior" (MWD), thus forming a unified 'symbolic medium' (Cox and Pezzullo 2015: 20) (see Platonova 2015 for discussion). This tendency shifts our perception of a communicative act, contributing to the establishment of multimodal and intersemiotic communication 
practice, where the former concerns multiplicity of communication modes, while the latter addresses multiplicity and interrelation of semiotic systems.

The openness of a semiotic system is determined by its ability to co-exist with other semiotic systems, as well as by the ability of a user to recognise and make possible use of its constituent elements inviting new meaning combinations and "creating multiple moments of interpretive possibility" (Albers and Murphy 2009: 4). Interpretation implies intersemiotic translation, especially for the multimodal messages, where verbal signs are read by means of non-verbal signs and vice versa (cf. Petrilli 2003: 18). The combination of elements from different semiotic systems requires a recipient to establish comprehensible intertextual and intermedial links to the previously acquired set of knowledge to grasp the meaning of a message, which can be displayed both verbally and visually. The communicated message is defined as "meaningful combination of terms in a semiotic system" (Purchase and Naumann: 2014), whereas; "a physical realization of a message" is seen as a text (ibid), hence, following Albers and Murphy (2009), all forms of semiotic systems in use create a text.

A visual metaphor is seen as one of the instances of a multimodal and intersemiotic message, which generates a text, a whole story being narrated to the recipients. It is revealed gradually uncovering numerous layers of meaning encoded within the very metaphor and within the whole visual, linguistic, and spatial settings it is placed in. The blending of different semiotic systems for metaphorical meaning transfer calls for a convenient analytical tool, which would explain the mechanisms of concept cognition (encoding, decoding), metaphorical mapping, and imagery exploited for message communication. Therefore, to ensure unambiguous communication of information provided within a multimodal and intersemiotic message a concept linking "the mimetic and the diegetic level" (Moser 2007: 336) is needed and it is the concept of "iconicity that serves as a mediator" (ibid) between them.

Metaphor-icon link is always foregrounded in the communicated message, but its structure may be different depending on the prevailing component. The author of the research gives tribute to the model for metaphor-in-icon and icon-inmetaphor analysis in cognitive terms proposed by Hiraga in 1998, which is an effective tool "for clarifying the complex interrelationship between metaphor and iconicity in the dynamic production of meaning in language" (Hiraga 1998). To establish theoretical framework of the given research the works of Anstey and Bull (2006) on different types of semiotic systems, of Petrilli (2003) on intersemiotic translation, of Wagner (1996), Wolf (1999) and Moser (2007) on intermediality and multimodality, as well as of Forceville (1996) on pictorial metaphors shall be addressed.

The dynamically developing interdisciplinary field of environmental communication is a great platform for investigation of the role and application of the visual metaphor, as within the given field the tendency to apply visual metaphors for information transfer is quite widespread. Visual metaphors used in 
different media to communicate information on environmental issues may frequently take a form of a social advertisement disseminated on posters, leaflets, and banners (both static and interactive). As a contribution to this idea, the author shall analyse the application of the visual metaphor 'global warming' as appearing on both printed and web posters, created for the needs of public awareness campaigns. The paper sets out to explore the notion of a visual metaphor and its role in communicating specialised information to mass audiences, paying particular attention to the emotive and heuristic components of meaning construal. The paper shall focus on the investigation of simultaneous manifestation of iconic and metaphorical mappings, analysing metaphor-in-icon and icon-in-metaphor links in the visual metaphor ' $g$ lobal warming'.

\section{Inter-nature of Meaning: Interdisciplinarity, intersemioticity, intermediality}

Analysis of meaning creation processes within the field of environmental communication is complicated by the fact that the nature of information transferred has changed. There has been a considerable shift towards extensive complexity of meaning at all levels (formation, organization and transmission).

Successful application of visual metaphors for the needs of professional communication demands approaching the concept of meaning and its role in the communicative process from the threefold perspective - as an interdisciplinary material, as an intersemiotic construct, and/or as an intermedial phenomenon. In other words, meaning within visual metaphors is efficiently decoded if a recipient is ready to address multiple scientific fields, recognise different symbols of multiple semiotic systems and accept information communicated via multiple media forms.

In the era when the borders between disciplines of knowledge are being blurred, addressing distinct scientific fields simultaneously is to a certain extent expected by the recipient of a message. The challenges occur due to the fact that this so called 'inter-nature' of meaning creates a platform for communication of intersemiotic and increasingly intermedial and multimodal information. It demands a high level of multiliteracy on the part of the recipient, which can be seen on different planes and concerns the ability of the recipient to make a more efficient use of the general skills and professional competences to:

- manipulate imagery and visualize it, generating a bond between mental images and visual representation;

- think creatively, "using cognitive processes to manipulate or act on stored knowledge" (Nevid 2015: 251);

- establish certain relations to the previously acquired set of knowledge, i.e. to generate intertextual and intermedial links; 
- to integrate perceptual and conceptual dimensions of meaning, where the former concerns the auditory, graphical and pictorial representation of the meaning-bearing component, e.g. word, compound, metaphor, etc.; while the latter refers to "the properties that constitute the meaning of the word" (following Massaro 1975: 12);

- demonstrate understanding of the isolated semiotic systems and of their combinations producing amalgam meaning, as "all semiotic resources are functional in the promotion of scientific learning" (Kress et al. 2001);

- deal with increasing (r)evolutionizing nature of content multimediality, which is seen as the gradual "passage from a received multimediality, to an interactive multimediality, to a built multimediality, to a reflective multimediality" (Dall'Aqua 2015: 219). In other words, it is a gradual transition from the content, which is pre-created, to the content, in the creation of which a user participates, to the content, which is created as a common social product, and, finally, to the self-creative content (cf. ibid).

Today, to create and communicate meaning in general and exploit visual metaphors in particular, a literate person "needs to understand both the conventions within each semiotic system and how combinations of semiotic systems work together to convey meaning within and across texts" (Marcuccilli Strop and Carlson 2010: 11). The signs used to produce and transfer meaning may belong to different semiotic systems which, according to Anstey and Bull (2006: 25), are the following:

\footnotetext{
Linguistic (oral and written), visual (still and moving images), auditory (musical and sound effects), gestural (facial expression and body language), spatial (layout and organization of objects and space).
}

The author shares the opinion of Iyer and Luke (2010:21), who treat "all forms of semiotic systems as texts". Moreover, the semiotic systems existing within one text "may overlap, co-occur, and work with or against the meanings of the other system(s)" (Albers and Murphy 2009: viii). It means that visual images can be read and recorded as texts, that images used to create visual metaphors "like texts are rhetorical and must use signs to express meaning" (Wagner 1996: 17).

Therefore, a multilitirate person should demonstrate a profound knowledge of semiotic theory, as "semiotics gives a foundation for the classification of signs according to different forms of iconicity" (May 2007 in Stathi 2014: 140). Iconicity or, as referred to by Wendorf (1990: 19), iconicism, implies, among all other factors, metaphorical incorporation of the elements and structures of one medium into the other (cf. ibid). This view is also supported by Stathi (2014: 147), who states that today within semiotic theories one should recognise that "...the making of meaning depends on, among other factors, processes of multimediality and intermediality...". In other words, in the communication of meaning encoded in the visual metaphor the elements of multiple semiotic systems are used 
simultaneously creating a unified multimodal form and establishing intermedial links to the previously gained knowledge.

At this point, it is significant to review if the multiplicity of elements of different semiotic systems existing within one message and communicated via different media should be addressed as a multimodal, multimedial, intermedial, and/or simply intersemiotic phenomenon. The author of the paper is aware of the concepts of trans- and plurimediality, as well as pluri- and transmodality, but within the present paper she does not attempt to historicise all these concepts, but to propose operational definitions for the needs of the present research.

Multimodality, as defined by Kress and van Leeuwen (1996: 183), exists in "any text whose meanings are realised through more than one semiotic mode". The combination of various semiotic modes for communication of meaning implies application of different elements, different information representing resources, which are incorporated within one text. Therefore, the choice of different modes is justified not only by the necessity to pursue clarity of information, but rather is governed by the principles of essential "resource integration and meaning compression" (Baldry and Thibault 2006: 18-19, in Gibbons 2012: 17).

Multimediality, in its turn, has gained a considerable focus due to digitalization of information and is seen as one of the key characteristics of the communication on the Internet, alongside with hypertextuality and interactivity (cf. Ibáñez and Alonso 2015: 92). It refers to the "integration of different media formats, audio, graphics, pictures, and text, into a single media form" (Siapera 2012: 136), which is aimed at providing a better and faster access to the global knowledge, rather than to individual knowledge. According to Wolf (2005: 254), multimediality exists if "two or more media are overtly present in a given semiotic entity at least in one instance". It means that the existing media forms can still be clearly recognised and, if necessary, treated individually.

Intermediality "refers to interconnectedness of modern media of communication" (Klaus Bruhn Jensen cited in Donsbach 2008: 2385-2387). In other words, different media evident within a certain semiotic entity are mixed together to form a unified message, and, therefore, cannot be clearly delineated from each other, as they "depend on and refer to each other, both explicitly and implicitly" (ibid). Intermedial relations are significant for understanding and communicating the whole message, as they "integrate perceptual and conceptual dimensions of the construction of linguistic meaning" (Moser 2007: 342) and serve as "a bridge between medial differences that is founded on medial similarities" (Elleström 2010: 12). Therefore, the author of the present research following Wagner (1996) theories proposes to correlate the concept of 'intermediality' with the concept of 'intertextuality', "where intertextuality is the mono-medial (verbal) and intermediality is the cross-medial variant" (Wolf 1999: 46), while both of them should be delineated as the forms of intersemiotic relations, existing between "different media in a multitracked text" (Nelson 2010: 13). 
It means that irrespective of the fact whether transformation of the content from one form to another or simultaneous application of various media forms have been applied for creation of the message, it demands the recipient to understand the basic principles of transmutation or intersemiotic translation, as eventually it is all "a matter of perception and interpretation" (Nelson 2010: 13).

Discovering and interpreting intersemiotic messages makes a recipient experience a variety of different marginal emotions, e.g. joy-sadness, trustdisgust, fear-anger, anticipation-surprise, which can be further explored and analysed following, for instance, Plutchik's Theory of Emotions (1980). The emotional path to interpretation of the whole message and to the discoveries of new meanings is, perhaps, the fastest one, as most of our thoughts and actions are governed by emotions; but this path is not the most precise, as emotional response is always subjective and, frequently, hinders proper recognition of all semantic layers of meaning.

Instant and precise interpretation of visual metaphors is complicated by the fact that pictorial representation of the genuine object may to a certain extent be in conflict with recipients' perceptual and conceptual apparatus, i.e. it would appeal to emotions recipients are unwilling to experience, or would evoke allusions to the phenomena recipients are reluctant to consider. It means that the icon within a visual metaphor is seen as an efficient manipulative instrument, which is aimed at appealing directly to the aspirations, demands, beliefs and even immediate emotional state of the recipients, motivating them to act in a certain way, and, hence, influencing their behavior and decision-making. This assumption leads to the question, which shall be explored in the following sections, i.e.: How visual metaphors can be exploited to create a unique message, which communicates a universal challenge and is understandable irrespective of the linguistic background and professional expertise?

\section{Visual metaphor}

There is an ongoing discussion on the nature of visual metaphors, which are frequently seen as visual manifestations of corresponding verbal metaphors.

The author gives tribute to Forceville (1996) for the detailed critical survey of the studies addressing the concept of visual, or as termed by Forceville (ibid), pictorial metaphor, providing framework for its analysis and advocating in favour of Conceptual Metaphor Theory, which states that "metaphor is primarily a matter of thought and action, and only derivatively a matter of language" (Lakoff and Johnson 1980: 153). Theoretical and empirical research he conducted paved the way for future interdisciplinary investigations of the application of visual metaphors, which are seen as independent multimodal constructs that convey the message combining the elements of various semiotic systems.

Nevertheless, the sceptics still disregard the very notion of a visual metaphor, stating that "visual metaphors are nothing but the illustrations of commonplace 
metaphors that already exist antecedently in language" (Caroll 2001: 202), i.e. they assert that there are no visual metaphors. This argument is supported by the fact that most of the visual metaphors can be relatively easily expressed on a verbal plane.

Visualisation of the verbal content establishing both metaphorical and iconic mappings is seen as being opposite to the verbalisation of the visual content, where iconic and metaphorical mappings are rather 'vividly explained' exploiting such rhetoric device as ekphrasis, which in general concerns "the verbal representation of visual representation" (Heffernan 1993). Reproduction of the image in verbal content is never precise, nor it is complete, as ekphrasis "is always less and more than the original visual sign" (Boehm 1995: 30). Eventually, ekphrasis is aimed at describing the visual artefact as vibrantly and precisely as possible, so that readers of this message can live the same emotions and feel the same aesthetic pleasure as if they saw the image themselves. However, it does not mean that verbal variant of the visually originated metaphor will retain metaphoric nature, as "description of metaphor simply does not have the power of the metaphor it describes" (Danto 1981: 172-173).

In other words, not all visual metaphors can be converted into verbal metaphors, and even if they can be reduced to the verbal statement, it does not guarantee the concordance of all its meanings in both semiotic systems.

\footnotetext{
One mode's potential to render "meaning" can never be completely "translated" into that of another mode - and sometimes translation is downright impossible. For this reason alone, a healthy theory of (cognitive) metaphor must systematically study non-verbal and multimodal metaphor (Forceville and Urios-Aparisi 2009: 4).
}

Visualisation of a metaphor can make it broader or narrower than its verbal variant, it can establish a better rapport with the target audience due to clearly depicted meaning in use, finally, it can ensure a faster and better recognition of the metaphorically encoded meaning.

It means that a visual metaphor produces a unique story narrated through the mechanisms of both metaphorical and iconic mapping. Metaphorical and iconic mappings are simultaneously contributing to the transfer of a message, as the image used relates the pictorial dimension, linguistic meaning and "invites the user to consider its heuristic value" (Caroll 2001: 211). Users may identify new connections between the elements of the semiotic systems used to create a visual metaphor. They are invited to discover the stages of a visual metaphor construction, recognising "metaphoric mapping from the concrete to the abstract domain" (Demey et al. 2008: 194), and exploring "iconic mapping from the concrete source domain to the linguistic domain" (Demey et al. 2008: 194). It means that information encoded in the target domain is communicated metaphorically employing the "iconic depiction of the source domain" (Taub 2001: 97). 
The mechanisms of iconic and metaphorical mapping are similar as they both "share that property of signification 'motivated' by similarity" (Hiraga 1998). However, similarity is both treated and manifested differently since in metaphorical mapping similarity is rather presupposed and/or represented in a schematised and abstract way. It is an ongoing never-complete process, as metaphorical links can be generated and/or established in the process of mapping one conceptual domain onto another conceptual domain (cf. Lakoff and Johnson 1980). In iconic mapping, similarity rather relies on object resemblance, replicating the shape, appearance or structure of an object, which makes icons "easy to understand because their resemblance to the objects is immediate and concrete" (Hiraga 1998).

While "a metaphor, like an image or an analogy, is what it represents - but not because of an antecedent identity or similarity, not as a reminiscence, but in virtue of a similarity which it creates" (Anderson 1984: 459, in Hiraga 1998).

It means that metaphorical mapping creates almost infinite number of meanings and their possible interpretations, as "the particular content of a metaphor can be said to constitute an interpretation of reality in terms of mental icons that literally allows us to see what is being talked about (italics in the original)" (Danesi 1995: 266). Moreover, metaphorical mappings can even lead to interpretations, which were not intended by the authors of the message.

In visual metaphors, iconic representation is frequently seen as being dominant over the metaphorical component in the overall meaning construction, as the links established between the icon and the object it resembles are evident to people irrespective of their background knowledge and expertise. However, "it is a mistake to suppose that visual metaphors can only induce object-comparison and cannot mobilize knowledge of connotations" (Caroll 2001: 359). The pleasure and great aesthetic value in creating and using visual metaphors lie in the fact that having initiated user imagination and evoked so many ideas and associations simultaneously, these metaphors nevertheless are not "being reduced to any definite thought" (cf. Kant 1790 (1964): 317-318). This factor makes visual metaphors a universal tool for attracting attention and communicating information irrespective of the linguistic competence, professional expertise and background knowledge of the recipient, as these metaphors are applied to address the shared challenges and they are constructed manipulating commonly recognised images.

Within the field of environmental communication, the tendency to apply visual metaphors for information transfer is quite widespread, due to explicit iconicity of the very concept 'environment' and related concepts of 'nature' and 'life'. The advocates of 'green thinking' tend to visualize information on environmental issues, which may frequently take a form of a social advertisement being disseminated on posters, leaflets, and banners within public awareness campaigns. This phenomenon can be well illustrated with the widespread use of the visual metaphor 'global warming'. 


\section{Case Study: Metaphor-Icon Links in Decoding Visual Metaphor 'Global Warming'}

Metaphor-icon links within visual metaphors can be based on metaphor-in-icon and icon-in-metaphor models (following Hiraga, 1998). The icon-in-metaphor model assigns dominant role to iconic mapping, which demands addressing the visual representation, i.e. the icon to construct the meaning of the whole metaphor. In this case iconicity encompasses the metaphorical component and metaphor is manifested on the visual plane, as clearly as no multiple readings are possible.

While the metaphor-in-icon model is a more complicated mechanism, as it implies primarily addressing the verbal element, first to relate it to iconic representation and, secondly, to grasp the meaning of the whole visual metaphor. The difficulty lies in the fact that decoding verbal message may lead to multiple interpretations and a user should be able to link the intended meaning of the verbal component with the provided visual element to properly understand the communicated message.

However, despite the fact that a user of the message is manipulated to think of a certain idea, $\mathrm{s} / \mathrm{he}$ is not guided to experience only a restricted set of emotions, and so $\mathrm{s} / \mathrm{he}$ is not controlled over the discoveries $\mathrm{s} / \mathrm{he}$ can make while reading the message. This assumption increases the role of emotive and heuristic components in creating visual metaphors in meaning formation and communication processes, which shall further be addressed analysing particular examples of a visual metaphor 'global warming' in use.

The 'global warming' metaphor is iconic by its very nature, as it is best comprehended in the pictorial dimension, because it creates a visual string of related images, which lead to complete understanding of the meaning encoded within the metaphor. Explicitness of the icon grants a deliberate freedom to the users of this metaphor to visualize its meaning components exploiting various semiotic systems and combining different communicative modes. It leads to generally numerous variants of a visual metaphor 'global warming', which, although, definitely share the key components and are aimed at achieving a unified result, are still communicated employing different means and appealing to different emotions.

The image of the Earth in the visual metaphor 'global warming' is frequently used in combination with signs belonging to other symbolic systems or with elements belonging to other semiotic systems, thus, producing a unique story narrated through the mechanisms of metaphorical and iconic mapping. These actions tend to evoke a wide range of emotions, which, however, all should lead to the idea of negative, even tragic effects global warming produces on the Earth. The negative effects produced on the planet are visualized as the Earth melting, sweating, heating, burning, boiling, warming, crying, being in a fever, in other words, secreting its essential fluids.

The image of the planet Earth in the visual metaphor ' global warming' may be represented in different ways and forms, e.g.: 
- photo - the genuine photo of the planet Earth accompanied with some additional symbols and/or verbal message;

- cartoon - an illustration of a personage with characteristics of a human being;

- graphical image - the schematic representation of the planet made using various graphical editors (usually implies combining elements of various systems);

- painting - an authorised artistic representation of an image of the Earth in pastel or oil colours (usually produced to pronounce the attitude of an artist towards a particular problem);

- drawing - an artistic creation of an image of the Earth (usually authorised and produced for the needs of a particular event).

The best effect is achieved when the authors of the posters choose to adjust the real photos of the planet Earth to the needs of their public awareness campaigns. The photos of the planet may be enhanced, artistically adjusted, their quality may range from blurred to superior, but the meaning they convey is still clearly understandable. Such pictures appeal directly to our knowledge of how the planet looks like and trigger the strongest emotions, as they are created as if depicting the current situation. Within the framework of the present research, the author focuses on the analysis of different posters containing iconic images of the planet Earth. To interpret the meanings communicated by the images on posters, advanced level of multiliteracy is expected on the part of the recipient, which requires the ability to think creatively, manipulate images, visualize associations, and generate intertextual and intermedial links.

In Figure 1, the Earth is shown as a melting ice cream. The image is a typical representation of the icon-in-metaphor model, as for the interpretation of the whole text it is most relevant to understand the visual code placed in the spatial setting. The planet Earth as the image of an ice cream placed against the dark surrounding background with the enlightened middle part may be interpreted as the light of still existing hope for the better life, if the proper actions are taken as soon as possible. 


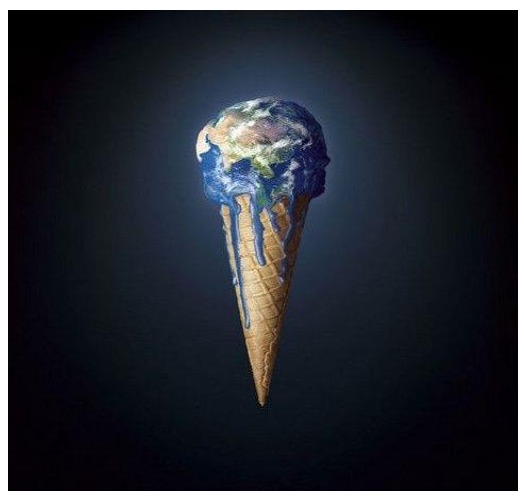

Figure 1. The Earth as the melting ice cream ${ }^{1}$

The same message can be communicated employing the metaphor-in-icon model, which would definitely demand addressing the verbal message first, assess it against the visual and spatial settings and, by adding these dimensions, interpret it.

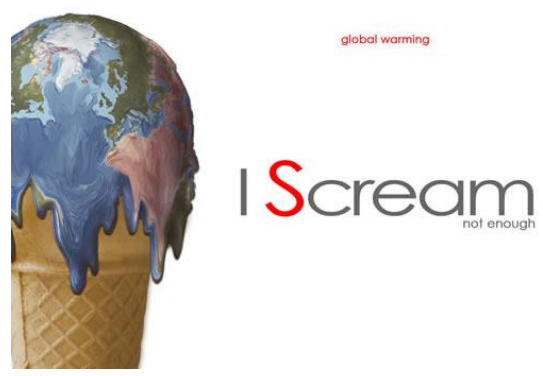

Figure 2. The Earth as the melting ice cream, text added ${ }^{2}$

The image given in Figure 2 is a great example of the intersemiotic message communicated on linguistic, visual and spatial planes. The reader is invited to notice the slogan, which is a homophonic pun of "I Scream" vs. "Ice cream". The latter is supported visually to guide the reader to the required interpretation. The image of the Earth is enhanced and artistically treated to intensify the effect if compared against the picture given in Figure 1, while the image of the waffle cone remains unadjusted. The message "not enough" written in small letters just beneath the slogan indicates insufficiency of the actions taken so far to fight the problem. It is interesting to note that in Figure 2 the visual metaphor is actually

1 Available from: http://vivredemain.fr/35-campagnes-creatives-wwf-reflechir. [Accessed: 30 May 2017].

2 Available from: http://www.hongkiat.com/blog/global-warming-alert-posters. [Accessed: 30 May 2017] 
named, as the slogan "global warming" is applied at the top of the poster, which, however, is not needed as the communicated message is understandable without tautological repetition of the same idea.

In Figure 3, the planet is frying on the pan, gradually losing its shape and essential fluids in the form of vapour. In the given case, the visual metaphor is constructed employing the elements of visual, acoustic and spatial semiotic systems.

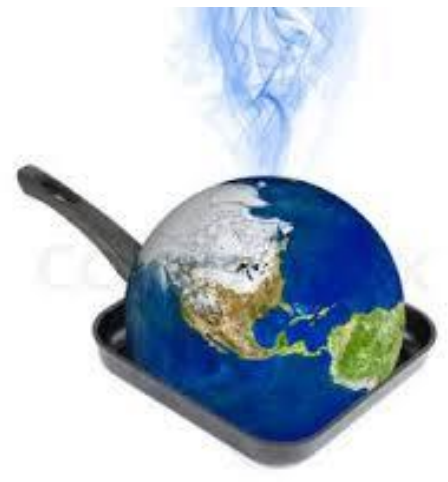

Figure 3. The Earth on the frying pan $^{3}$

If compared to the images communicated in Figures 1 and 2, the image seems to be less powerful and rather static, as time component is not well pronounced. This image created following the icon-in-metaphor model lacks the semantic component of inevitability, as it completely depends on the humanity whether to fire a pan or not, while in the case of ice cream, the balance is created artificially and is very fragile, as the ice cream is supposed to melt and disappear (be eaten) anyway irrespective of the fact if it is or it is not treated properly.

The use of icon-in-metaphor model for visual metaphor creation may imply application of the elements belonging to distinct symbolic media. This phenomenon is illustrated in Figure 4, where the photo of the planet Earth is hidden behind the transparent traffic sign NO ENTRY. The visual metaphor communicates multiple messages simultaneously and demands the user to understand intermedial nature of the visual metaphor to uncover its meaning(s). On the one hand, the use of the traffic sign clearly implies reasonable limitations on the use of vehicles, which produce emissions of $\mathrm{CO}_{2}$ to the atmosphere, hence, contributing to intensifying global warming effects. On the other hand, the traffic sign restricts the use of any vehicles including environment-friendly bicycles, which can be treated as an invitation to reconsider the very concept of green logistics, or even as a warning not to welcome any humans. Placement of the traffic sign over the image of the whole planet indicates the scale of the problem.

3 Availbale from: https://www.123rf.com/photo_6587701_global-warming-concept-earth-at-thefrying-pan-isolated-on-white.html. [Accessed: 30 May 2017] 
The message is intensified by the choice of colours for the slogan and background. The colours of the slogan "global warning", which is seen as a pun to "global warming", are the same as the colours of the road sign, which are placed against the very dense black background. The red colour for "warning" is used on purpose to allude to "warming", intensifying the meaning of being very warm, even hot.

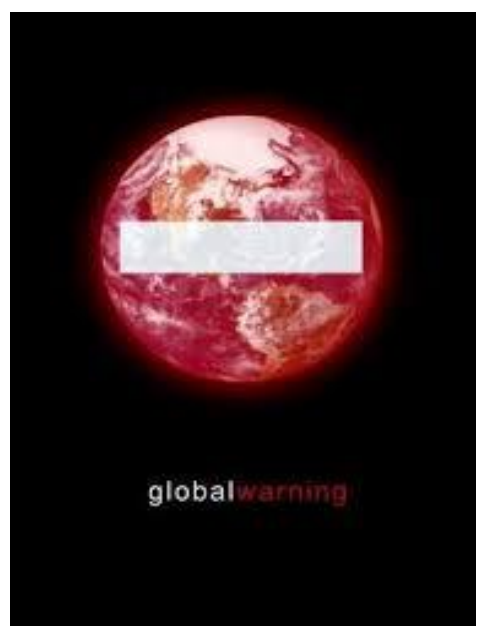

Figure 4. The Earth bearing NO ENTRY sign ${ }^{4}$

The combination of different visual and verbal factors intensifies the meaning of the multimodal message and stimulates the thinking process, inviting both intertextual and intermedial links, as well as welcoming unique and expected interpretations. The use of verbal components on the poster makes the user consider either words or image(s) in the first order, which would influence the interpretation path.

Figure 5 illustrates the abovementioned phenomenon. A human hand holding the lighter, which heats the planet illustrates the influence of the mankind on the Earth. The question "Why?" put at the bottom of the poster is a rhetoric one. The slogans placed on the posters may frequently take the form of the rhetoric open questions with multiple subjective answers. The questions pronounced on the posters suggest acoustic perspective, as depending on the way you literally ask it you may induce different reaction within the audience.

\footnotetext{
${ }^{4}$ Available from: https://uk.pinterest.com/pin/553379872935921646/. [Accessed 14 June 2017]
} 


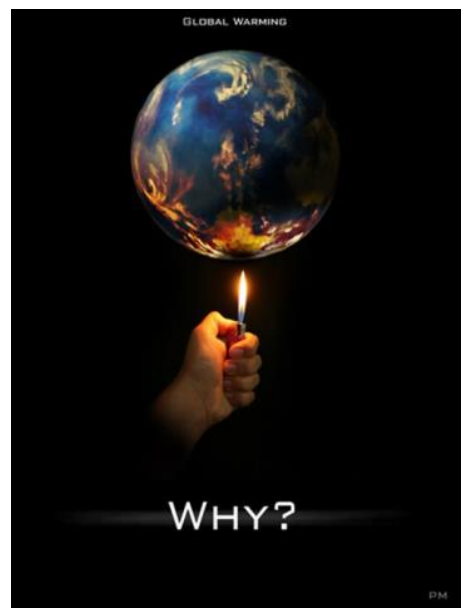

Figure 5. The Earth being heated by a lighter ${ }^{5}$

The concept of fire as the summative visual representation of the effect produced by human beings on the planet Earth is applied in versatile forms. The use of the image of fire is unambiguous allusion to the concept of global warming, which is clearly associated with reaching high temperatures.

Figure 6 contains the image of the Earth, which is represented as the melting candle. The visual metaphor in Figure 6 is created following the metaphor-in-icon model, with the allusion to the idiomatic expression "Plan B", which stands for the backup plan in case plan A fails. In the given case, the visual metaphor of the melting candle is applied to intensify the meaning expressed on the linguistic plane, as the role of the verbal message is dominant. The slogan goes "There is no planet $B$ [intermission, no syntactic signs] Act now.", which invites the target audience to consider the tragic consequences of their inactivity and even careless laziness. The component of time is pronounced in both visual and verbal messages. In the former, the influence of time is illustrated with the burning candle, as the time required for the candle to burn down completely is very short. In the verbal message, the semantic component of time is indicated with the full stop at the end of the sentence "Act now.", specifying the absence of time for decision-making. This dual indication makes the sense of inevitability of the tragedy evident. However, the very image communicates the illusion of the existing control over the situation, which is supported by the fact that we can decide whether to light up the candle.

5 Available from: https://www.pinterest.com/pin/518336238339889740/.

[Accessed 16 June 2017] 


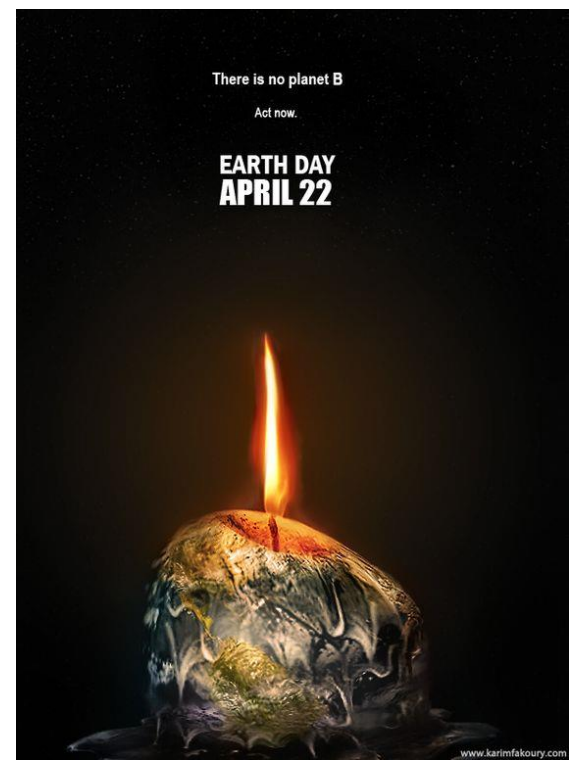

Figure 6. The Earth as the burning candle ${ }^{6}$

It is interesting to note that both Figure 5 and Figure 6 are created employing the image of open fire against the dense black background. However, in Figure 5 black background colour is required to intensify the damage caused by the fire of the lighter (as flame is better visible against dark background), while in Figure 6 the flame of the candle creates a path of light and points at the slogan and the exact date, inviting people to start thinking green first on the Earth Day on April 22, and later continue maintaining the same attitude throughout their lives.

The call for certain action, which in the opinion of public awareness campaign authors should be taken by the humans, can be expressed in the form of directives, which invite and even command people to act in a certain way. The verbal message is then supported by the visual message, establishing a clear metaphorin-icon link between them.

The verbal metaphor used in Figure 7 "Let the Earth sleep" can be interpreted as an invitation, an order, a command, an advice, a request; finally, as a plea ranging from the woeful cry to horrid yell, which requires addressing the acoustic perspective for the interpretation of the multimodal message. The concept of sleeping reflected in the verbal metaphor conceptually suggests treating the Earth as the human being, and implies such components as proper rest, absence of acoustic and visual pollution, and full restoration, which are essential to ensure sound living.

6 Available from: https://www.pinterest.com/pin/562668547176596438/.

[Accessed on 16 June 2017] 


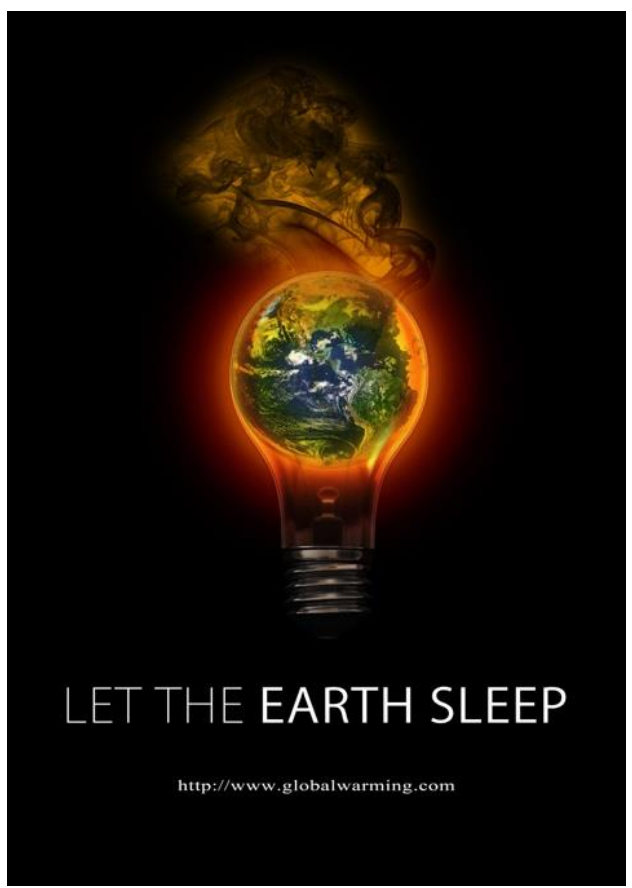

Figure 7. The Earth as the burning light bulb ${ }^{7}$

The visual metaphor of sleeping is expressed with the help of the image of a light bulb. The metaphor has a dual reading, as on the one hand, the light bulb represents the surrounding acoustic, visual and other kinds of pollution, which disturb the Earth from having rest. For the proper rest, the light bulb should be switched off, thus creating the desired atmosphere of pleasant silence and nightfall. While, on the other hand, the light bulb can be treated as the symbol of the planet itself, which is heated to the utmost and emits black and flame-colour vapours, which most probably should be accompanied with unpleasant sound of light bulb breaking (thus adding the acoustic dimension), as well as with unpleasant smell of light bulb burning. In this case, the light bulb placed against the very dense black background, is used, in a way, to symbolise the powerlessness and illustrate the inability of the light bulb to enlighten the surrounding. It can be read as the absence of hope if the Earth is not allowed to revive.

Some of the posters used for the needs of social campaigns do not actually invite to take actions, but simply state the current situation (see Figure 8). The power of such visual metaphors is hidden in the fact that they simultaneously allow minimum interpretive freedom (containing clearly expressed idea) being

7 Available from: http://www.coroflot.com/capioxy/Global-Warming-Poster-Graphic-Design. [Accessed on 15 June 2017] 
highly subjective and evoking the emotions, which many people are reluctant to think of and experience.

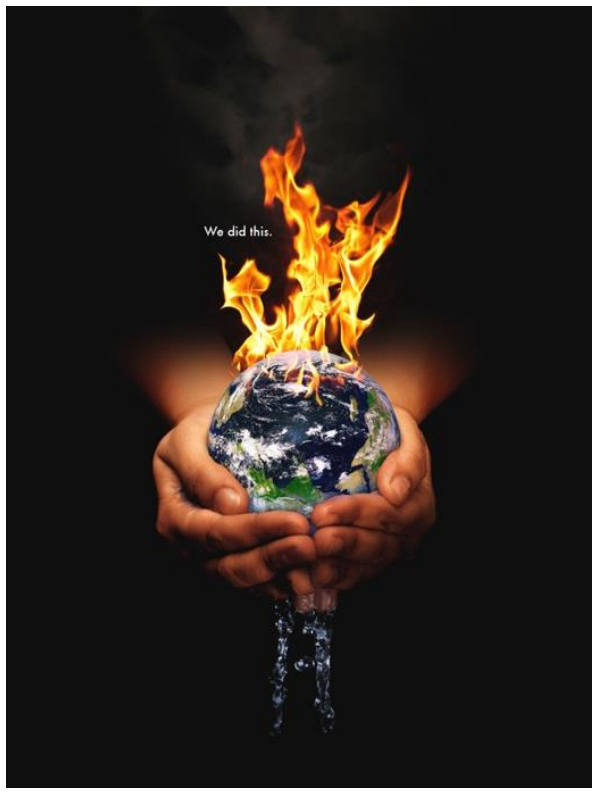

Figure 8. The Earth on fire and secreting the fluids ${ }^{8}$

In Figure 8, a human is holding the planet Earth in one's hands, the planet is burning on the top and is secreting the essential fluids at the bottom. There is a visual metaphor of the Earth in a way bleeding hidden within the visual metaphor of global warming. Just as the human is committed to die having lost a substantial amount of blood, the Earth is going to perish having lost its water resources. The slogan used for the present poster states "We did this.". The full stop at the end of the slogan is very unusual and in this case it is used to escape any other readings and interpretations of the given statement, which can be interpreted as "This is it. "We did this. No one else to blame". The sense of tragedy present in the given figure leaves very little for the light of hope. The poster is basically the last and final call to take the required actions, which were implicitly pronounced and hinted in Figures 1-3, and were obviously invited and proposed in Figures 4-7, analysed within the framework of the present paper.

The decision to visualize environmental issues on printed and web posters is substantiated by the fact that information dissemination capability of the given medium is very high. The 'global warming' issue is reflected in numerous artistic works, papers, posters, advertisements, and is supported via an impressive number of poster competitions and advertisement festivals.

\footnotetext{
${ }^{8}$ Available from: https://www.behance.net/jacobbrcic. [Accessed 20 June 2017]
} 


\section{Concluding Remarks}

The intersemiotic approach to message creation shifts our perception of data collection, procession, and representation, welcoming active use of the elements belonging to distinct symbolic media and different semiotic systems, as a result producing texts with the presence of the elements of linguistic, visual, and spatial systems, and even with the imaginative manifestation of the elements of the acoustic system (implying considering the tone, pauses, pace and intonation when reading the message) and gestural system (considering the expressions and gestures in motion). Visual metaphors are generally constructed simultaneously encompassing the elements of at least three semiotic systems, hence creating a unified multimodal form and establishing intermedial links to the previously gained knowledge.

Application of visual metaphors, created following both metaphor-in-icon and icon-in-metaphor models, for communication of sensitive issues within the framework of public awareness campaigns is a very powerful tool, which can ensure equal effect in different linguistic communities, producing a unique story narrated through the mechanisms of metaphorical and iconic mapping. The use of the icon-in-metaphor model is frequently given priority due to its less ambiguous nature, as the links established between the icon and the object it resembles are transparent to people irrespective of their mother tongue, expertise, and to a certain extent, irrespective of their background knowledge.

Visualisation of 'global warming' effects raises topical issues in an understandable, concise and very precise way, ensuring maximum information coverage framed by minimum interpretive guidelines. Therefore, interpretation of the text communicated by visual metaphor is a fascinating exercise, as despite the fact that it seems to express the obvious reality, such text encompasses unique heuristic value and aesthetic pleasure in discovering multiple layers of meaning.

\section{References}

Albers, Peggy and Sharon Murphy. 1999. Telling Pieces. Art as Literacy in Middle School Classes. Taylor and Francis.

Anderson, Douglas. 1984. Peirce on Metaphor. Transactions of the Charles S. Peirce Society: A Quarterly Journal in American Philosophy 20(4), 453-468.

Anstey, Michelle and Geoff Bull. 2006. Teaching and Learning Multiliteracies: Changing Times, Changing Literacies. Newark, DE: International Reading Association.

Boehm, Gottfried. 1995. Bildbeschreibung. Über die Grenzen von Bild und Sprache. In Boehm, Gottfried; Pfotenhauer, H. (Hg.): Beschreibungskunst - Kunstbeschreibung. Die Ekphrasis von der Antike bis zur Gegenwart, München, 23-40.

Caroll, Noel. 2001. Beyond Aesthetics. Philosophical Essays. Cambridge University Press.

Cox, Robert, and Phaedra C. Pezzullo. 2015. Environmental Communication and the Public Sphere, 440. SAGE Publications; $4^{\text {th }}$ ed. 
Dall'Aqua, Luisa. 2015. Orientism Management (OM): A New Framework to Manage Decisions and Hyper Dynamic Knowledge Process in a MultiUser Network. In Alok Kumar Goel and Puja Singhal (eds.), Product Innovation through Knowledge Management and Social Media Strategies. IGI Global.

Danesi, Marcel. 1995. The Iconicity of Metaphor. In Marge E. Landesberg (ed.), Syntactic Iconicity and Linguistic Freezes: The Human Dimension, 265-284. Berlin: Mouton de Gruyter.

Danto, Arthur. 1981. The Transfiguration of the Commonplace. Cambridge, MA: Harvard University Press.

Demey, Eline, Van Herreweghe Mieke and Myriam Vermeerbergen. 2008. Iconicity in Sign Languages. In Klaas Willems and Ludovic De Cuypere (eds.), Naturalness and Iconicity in Language, 189-214. John Benjamins Publishing Company.

Elleström, Lars. 2010. The Modalities of Media: A Model for Understanding Intermedial Relations. In Lars Elleström (ed.), Media Borders, Multimodality and Intermediality 11-48. Hound- mills, Basingstoke and Hampshire: Palgrave MacMillan.

Forceville, Charles. 1996. Pictorial Metaphor in Advertising. Routledge.

Forceville, Charles and Eduardo Urios-Aparisi (eds.). 2009. Multimodal Metaphor. Applications in Cognitive Linguistics, Vol. 11. Berlin: Mouton de Gruyter.

Gibbons, Alison. 2012. Multimodality, Cognition and Experimental Literature. Routledge studies in Multimodality: 3. Routledge.

Heffernan, James A. W. 1993. Museum of Words: The Poetics of Ekphrasis from Homer to Ashbery. Chicago: University of Chicago Press.

Hiraga, Masako K. 1998. Metaphor-icon Link in Poetic Texts: A Cognitive Approach to Iconicity. Journal of the University of the Air, No. 16. 95-123.

Ibáñez, Daniel Barredo and Martin Oller Alonso. 2015. Multimedia resources and Sporting Bias in MARCA.com and SPORT.es: An Analysis of Matches between Real Madrid C.F. and F. Barcelona in 2010-11. In Simon Gwyn Roberts (ed.), Sport, Media and Regional Identity, 91104. Newcastle upon Tyne: Cambridge Scholar Publishing.

Iyer, Radha and Luke Carmen. 2010. Multimodal, Multiliteracies: Texts and Lietracies for the $21^{\text {st }}$ Century. In Darren L. Pullen and David R. Cole (eds.), Multilietracies and technology Enhanced Education: Social Practice and the Global Classroom, 18-34. IGI Global.

Jensen, Klaus Bruhn. 2008. Intermediality. In W. Donsbach (ed.), International Encyclopedia of Communication, 2385-2387. Malden, MA, USA: Blackwell Publishing Ltd.

Kant, Immanuel. 1790. [1964]. The Critique of Judgement. In Hofstadter and Kuhns (eds.), Philosophies of Art and Beauty: Selected Readings in Aesthetics from Plato to Hedegger, New York: Modern Library.

Kress, Gunther and Theo van Leeuwen. 1996. Reading Images: The Grammar of Visual Design, London: Routledge.

Kress, Gunther, Jewitt, Carey, Ogborn, Jon and Charalampos Tsatsarelis. 2001. Multimodal Teaching and Learning: The Rhetorics of the Science Classroom. London: Continuum.

Lakoff, George and Mark Johnson. 1980. Metaphors We Live By. Chicago: Chicago University Press.

Marcuccilli Strop, Janice and Jennifer Carlson. 2010. Multimedia Text Sets. Changing the Shape of Engagement and Learning. Portage and Main Press.

Massaro, Dominic W. 1975. Understanding Language. An Information-Processing Analysis of Speech Perception, Reading and Psycholinguistics. Academic Press, INC.

May, Michael. 2007. A Semiotic Framework for the Semantics of Digital Multimedia Learning Objects. 14 $4^{\text {th }}$ International Conference on Image Analysis and Processing Workshops, 2007. ICIAPW 2007. 33-38. Los Alamitos, CA: IEEE Computer Society Press.

Moser, Sybylle. 2007. Iconicity in Multimedia performance: Laurie Anderson's White Lily. In Elżbieta Tabakowska et al. (eds.), Insistent Images, 232-347. John Benjamins Publishing Company. 
MWD - Merriam Webster Dictionary - Available from: http://www.merriamwebster.com/dictionary/communication. [Accessed on 9 June, 2017].

Nelson, Robin. 2010. Introduction: Prospective Mapping and Network of Terms. In S. Bay-Cheng, C. Kattenbelt, A. Lavender and R. Nelson (eds.), Mapping Intermediality in Performance, 1324. Amsterdam University Press.

Nevid, Jeffrey, S. 2015. Essentials of Psychology. Concepts and Applications. Cengage Learning.

Petrilli, Susan. 2003. Translation, Translation. Amsterdam and New York, Rodopi.

Platonova, Marina. 2015. Applying Emotive Rhetorical Strategy to Environmental Communication in English and Latvian. In Procedia: Social and Behavioural Sciences, 107-113. Vol. 236., Elsevier.

Plutchik, Robert. 1980. Emotion: Theory, Research, and Experience: Vol. 1. Theories of Emotion 1. New York: Academic Press.

Purchase, Helen and Daniel Naumann. 2001. A Semiotic Model of Multimedia: Theory and Evaluation. In Syed Mahbubur Rahman (ed.), Design and Management of Multimedia Information Systems: Opportunities and Challenges, 1-21. Idea Group Publishing.

Siapera, Eugenia. 2012. Understanding New Media. SAGE Publications LTD.

Stathi, Irini. 2014. Film and New Art Media Semiotics: On the Figural. In Evripides Zantides (ed.), Semiotics and Visual Communication: Concepts and Practices, 139-149. Newcastle upon Tyne: Cambridge Scholar Publishing.

Taub, Sarah. 2001. Language from the Body. Iconicity and Metaphor in American Sign Language. Cambridge: CUP.

Wagner, Peter. 1996. Introduction: Ekphrasis, Iconotexts and Intermediality - the State(s) of the Art(s). In Wagner Peter (ed.), Icons-Texts-Iconotexts. Essays on Ekphrasis and Intermediality, 1-42. Walter De Gruyter \& Co.

Wendorf, Richard. 1990. The Elements of Life: Biography and Portrait-painting in Stuart and Georgian England. Clarendon Press.

Wolf, Werner. 1999. The Musicalization of Fiction: A Study in the Theory and History of Intermediality. Internationale Forschungen zur Allgemeinen und Vergleichenden Literaturwissenschft 35. Amsterdam: Rodopi.

Wolf, Werner. 2005. Intermediality. In David Herman, Manfred Jahn, and Marie-Laure Ryan (eds.), Routledge Encyclopedia of Narrative Theory, 252-256. London: Routledge. 